\title{
The Role of Real Estate in the Portfolio Allocation Process
}

\author{
Jarl G. Kallberg \\ Crocker H. Liu \\ D. Wylie Greig
}

\begin{abstract}
This study explores the role of direct real estate investment in a portfolio context incorporating the real estate imperfections of indivisible assets and no short sales. Mean-variance efficient portfolios are calculated using Treasury-bills, bond and equity indices together with cash flows and appraised values from a set of twenty-two properties having an aggregate appraised value of \$336 million. Real estate diversification benefits are shown to be the greatest with smaller properties and are most advantageous at higher target levels of return. The study suggests that a 9\% allocation to real estate is optimal, rather than the $20 \%$ figure suggested in other studies.
\end{abstract}

The majority of studies that explore the role of real estate in a portfolio context either attempt to identify the optimal allocation of real estate in a mixed asset portfolio, hereafter known as the macro-approach, or focus on property diversification within a real estate portfolio, the micro-approach to real estate investing, using the standard mean-variance portfolio methodology. ${ }^{1}$ In these studies however, no attempt is made to link the two approaches to real estate investing. In addition, only a few studies attempt to incorporate the "imperfections" associated with real estate such as the indivisible or lumpy nature of real estate, which affect the portfolio allocation process. ${ }^{2}$

\footnotetext{
${ }^{1}$ Recent studies which attempt to identify the optimal allocation of real estate in a mixed asset context include Fogler (1984), Firstenberg, Ross and Zisler (1988) and Ennis and Burik (1991). These studies conclude that real estate should comprise between $10 \%-20 \%$ of an efficiently diversified portfolio. The percentage allocated to real estate varies in each study depending on the real estate return series used. Fogler (1984) assumes that both stocks and real estate have identical risk with the return on real estate less than the return on stock due to limited marketability associated with real estate. On the other hand, Firstenberg, Ross and Zisler (1988) use two appraisal based return series and correct these series for appraisal smoothing given the finding of Hoag (1980) that smoothing leads to a downward bias in the variance. Ennis and Burik (1991) use REIT returns since they argue that real estate returns should exhibit a positive relationship to stock returns and both Fogler (1984) and Firstenberg, Ross and Zisler (1988) assume that real estate is uncorrected with stocks.

${ }^{2}$ The studies by Fogler (1984), Firstenberg, Ross and Zisler (1988) and Ennis and Burik (1991) assume that no imperfections exist for real estate or get around real estate imperfections by focusing on real estate securities. These real estate imperfections include limited marketability, indivisibility or lumpiness of assets, no short sales and limited publicly available information. One exception to this is the study by Friedman (1971) who modifies the quadratic MPT decision problem to address the integer problem associated with real estate \{e.g., real estate is indivisible). Findlay et al. (1979) suggest an alternative modification to the MPT algorithm to recognize the lumpiness of real estate. While the study suggests a useful methodology for generating the efficient frontier for an all real estate portfolio, no attempt is made to deal with the mixed asset portfolio problem where some assets are divisible while other assets are lumpy.
} 
The purpose of this study is to investigate a more fundamental approach to the assessment of the risk and return tradeoff using detailed cash flow data on individual real estate properties. In essence, this research simultaneously analyzes the macro- and micro-perspective of real estate investing. More specifically, it explores the inclusion of specific real estate projects into the overall portfolio composition of stocks, bonds and real estate while explicitly recognizing the lumpy nature of real estate and the no short sales constraint in the mean-variance optimization process. This linkage is important because there is no guarantee that an efficient portfolio of stocks, bonds and real estate will make use of an efficient real estate portfolio (obtained from performing mean-variance optimization over all properties excluding all other financial assets).

The first empirical question examined is the optimal allocation to real estate. What is the optimal proportion allocated to real estate in a portfolio consisting of stocks, bonds and individual properties when the lumpiness of real estate and the no short sales constraint are accounted for in the optimization process? The second question examined is the exact portfolio optimization versus an approximation to the optimal selection of properties and risk-return consequences. How close is the return on a mixed-asset portfolio at a given level of risk when an algorithm, which simultaneously optimizes over all financial and real assets, is used relative to a sequential algorithm? The sequential algorithm first optimizes over all properties and then uses the resulting real estate portfolio to subsequently optimize over the remaining financial assets. The focus is on the sequential algorithm for several reasons. For one, some of the algorithms advocated for real estate portfolio analysis focus solely on within-asset diversification (see, for example, Findlay et al. 1979). A portion of the real estate portfolio literature also deals with intra-asset diversification which implicitly assumes that real estate is optimized separately from stocks and bonds. ${ }^{3}$ Recent evidence moreover suggests that the use of a sequential portfolio process is the norm in industry. More specifically, Bajtelsmit and Worzala (1995) found that the majority (60\%-70\% depending on the type of pension fund) of the general investment managers surveyed reported that asset allocation decisions between asset classes are made independently of within-asset class allocations. ${ }^{4}$

Consequently, the extent to which a heuristic alternative is a good approximation to the exact portfolio optimization algorithm is examined. The final empirical question is the changing composition of the mixed-asset portfolio. How does the optimal proportions devoted to stocks, bonds and T-bills change when real estate is added to a mixed asset portfolio? Does real estate tend to replace (or minimize the allocation) of any of these assets in the optimal portfolio? ${ }^{5}$

\footnotetext{
${ }^{3}$ For example, the study of Hartzell, Hekman and Miles (1986), focuses primarily on different grouping of real estate properties by geographic locations, growth, etc., in order to see which grouping results in higher returns although the study does provide correlations with stocks and bonds.

${ }^{4}$ Bajtelsmit and Worzala (1995) surveyed the general investment managers of the largest corporate, public and union pension funds. Of 397 managers surveyed, $24.2 \%$ of the managers responded. The sample is biased towards larger pension plans managing approximately $\$ 8$ billion on average.

${ }^{5}$ Prior studies have focused on a real estate index, which might tend to blur the impact of individual properties' correlations relative to bonds, bills or stocks in a portfolio.
} 
In investigating the role of real estate in the portfolio allocation process, the modified internal rate of return (MIRR) is used which focuses on cash flows. ${ }^{6}$

Section two discusses the data sources used in this study while section three describes the methodology used in the portfolio allocation process. Section four reports the findings and compares these results to the prior literature. Section five is the conclusion.

\section{Data}

This study employs quarterly, property-specific data on twenty-two properties from a large real estate fund for the time period starting March 1982 and ending June 1989. This represents thirty quarters of time series data. ${ }^{7}$ The properties are continuously held over the entire study period so that acquisition bias is not a problem. Information on each property in the dataset includes the following characteristics: (1) the net operating income per period; (2) the appraised value of the property in each quarter; (3) adjustments to appraised value, which reflects the fact that most commingled real estate funds use independent, outside appraisers only once a year (For the other quarters in the year, internal appraisals are performed. Thus, any differential between the internal and external appraisal in the period that the external appraisal is performed is recognized as an adjustment.); (4) the capital improvements added to the property in each quarter; (5) the standard metropolitan statistical area (SMSA) that the property is located in; and (6) the property type. Property types in the dataset include retail shopping centers, office buildings and industrial properties. There are neither apartment buildings nor hotel/motels in this database. ${ }^{8}$

Table 1 presents a summary description of the properties in the sample. It reveals that although $50 \%$ of the sample is comprised of industrial properties, office properties represent over $80 \%$ of the market value, with industrial and retail properties comprising approximately the remaining

\footnotetext{
${ }^{6}$ The MIRR is calculated by first discounting back to the present all outlays scheduled over time at the opportunity cost of capital. Next, cash flows are compounded forward at the appropriate reinvestment rate to the end of the holding period. Finally, the future value of a lump sum formula is used to compute the rate of return (MIRR) that makes the present value of outlays equal to the present value of the sum of compounded returns. The MIRR was used here since some of the properties had a negative cash flow over certain time periods and therefore the use of an IRR could result in multiple IRRs. The use of the MIRR in real estate portfolio analysis is further discussed in Graaskamp (1972) and Findlay et al. (1979).

${ }^{7}$ This study originally started out with data on forty-six properties. However, this number was reduced to twentytwo properties because not all of the properties had time series data for the full thirty quarters (e.g., some properties came into the portfolio through acquisitions and some properties left the portfolio due to property sales).

${ }^{8}$ Other attributes of the dataset that were not used include: (1) the property size in terms of square feet of net rentable area; (2) square feet of net rentable area that is vacant per quarter; and (3) the square feet of net rentable area that is occupied per quarter. These attributes were excluded since a preliminary analysis of the average return over the 1982 to 1989 correlated respectively with the total net rentable area, occupied space and occupied space as a percentage of net rentable area indicated that none of these correlations were important. More specifically, the correlations are respectively -.149, -.155 and .006.
} 
$10 \%$ and $8 \%$ respectively. On a regional basis, relatively few properties are from the East, while the Midwest, South and West have a fairly even representation in the portfolio.

Table 1 - Property description with market value in 000 's in twenty-two continuously held properties.

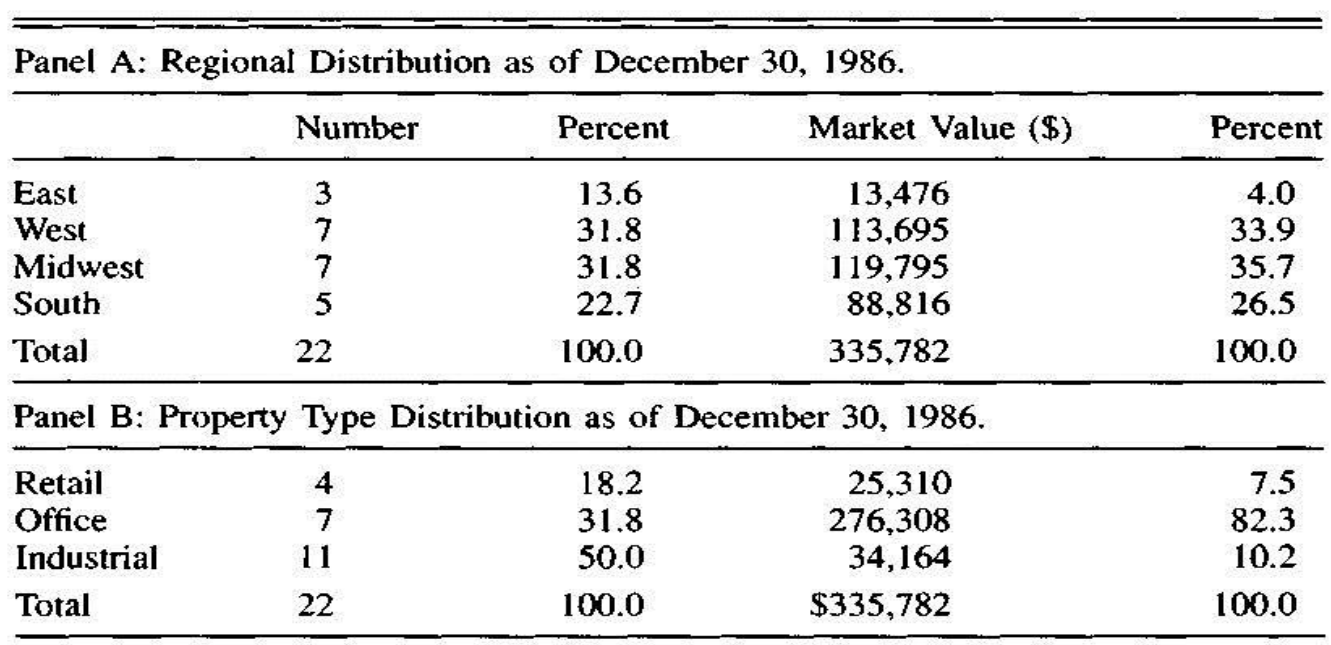

To generate the data, the following steps were taken. First, realized annual returns were obtained for Treasury bills, for average AAA-corporate bond yields and for the S\&P 500 over the 1982-1989 period from Ibbotson Associates SBBI 1991 Yearbook. ${ }^{9}$ To generate the modified IRR per year on the properties, the quarterly cash flows were compounded over the given year forward to the end of the year using the rate on the 3-month T-bill with the flows at the beginning of each quarter. Outside, independent appraisal values were used as the beginning and end of the year property values in calculating the MIRR. Due to the relatively few number of observations for each return series, all properties that did not have outside appraised values available from the first quarter of 1982 to the first quarter of 1989 were deleted. This left twenty-two properties.

Several reasons exist for using an annual rather than quarterly return series. For one, imputing values vis-a-vis cap rates with quarterly data generates unrealistically high variances. Secondly, a pronounced seasonality is present in the appraisal process that Commingled Real Estate Funds (CREFs) use, since CREFs typically use an outside independent appraiser for only one quarter during the year. For the remaining three quarters, an internal appraisal is made with the value typically adjusted upwards for the capital improvements made during a quarter on the presumption that a dollar's worth of capital improvements increases the value of the property by a dollar.

\footnotetext{
${ }^{9}$ The Treasury bill return is computed as the annualized return from rolling over 3-month iT-bills. The 3-month Tbills were used as a portfolio choice to be more consistent with the MIRR calculations. However, the tests were run using a 1-year T-bill with very minimal, if any, changes in the results.
} 
Figure 1 - Aggregate appraisal values.

This figure shows the seasonality effect which is present in the appraisal process given that CREFs typically use an outside independent appraiser for only one quarter during the year. For the remaining three quarters, an internal appraisal is made with the value typically adjusted upwards for the capital improvements made during a quarter on the presumption that a dollar's worth of capital improvements increases the property's value by a dollar. For the CREF used in the current study, all properties were appraised by an independent appraiser during the same quarter for each year. This suggests that the quarterly volatility estimates will be greatly distorted.

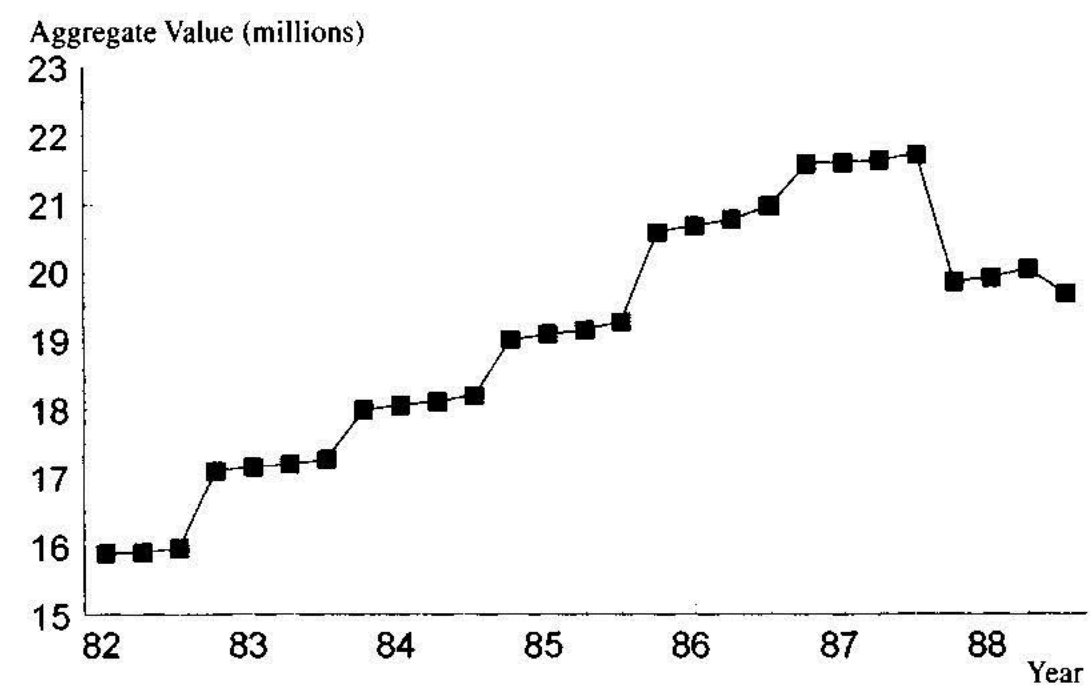

As a consequence, almost all changes in value are occurring at the annual external appraisal. This suggests that the quarterly volatility estimates will be greatly distorted. ${ }^{10}$ Figure 1 shows this seasonality.

\section{Methodology}

The basic optimization approach to including real estate investments in a portfolio consisting of stocks and bonds is to solve a mixed zero-one non-linear program. The discrete (zero-one) aspect of the problem comes from selecting the possible real estate projects, since the natural assumption is that they are indivisible assets. The remaining aspect-choosing among various financial assets - can be viewed as continuous. Formally, the mathematical program corresponding to the real estate investment decision is modeled as a parametric, quadratic, 0 1 program. Formally,

\footnotetext{
${ }^{10}$ Although Firstenberg, Ross and Zisler (1988) and Ross and Zisler (1991) propose methodologies to correct for smoothing in appraisal based returns that essentially increase the variance while leaving the estimate of the mean unchanged, quarterly volatility estimates will still be distorted if these approaches are applied to our data because of the three quarters of internal appraisals in a year in which relatively little or no change in value occurs. All significant jumps in the data are occurring at the external appraisal.
} 


$$
\begin{array}{ll}
\quad \mu^{T} d & \\
d=(S, B, x) & \\
\text { s.t. } & d^{T} \Sigma d=\sigma^{*} \\
& x_{i} \in(0,1) \quad \forall i=1, \ldots, n \\
& S+B+x^{T} p \leq K ; \quad S, B \geq 0
\end{array}
$$

where

$d=$ the decision vector comprised of the nonnegative quantities;

$S$ and $B=$ are the investment in equity and a bond index fund, respectively; ${ }^{11}$

$x=\left(x_{1}, \ldots, x_{n}\right)$ is a vector with each $x_{1}$, representing acceptance

$\left(x_{i}=1\right)$ or rejection $\left(x_{i}=0\right)$ of real estate investment $i$;

$\mu=$ the vector of mean returns on the stock index, the bond index and the $\mathrm{n}$ real estate investments;

$\sum=$ the corresponding covariance matrix;

$\sigma^{*}=$ a parameter, the overall portfolio variance, which is used to trace out the mean-variance efficient frontier;

$\rho=\left(\rho_{1}, \ldots, \rho_{n}\right)$ is a vector with each pi representing the cost of real estate investment on property $i$; and

$\mathrm{K}=$ an upper bound on the total investment size.

Essentially, each point on the efficient frontier is created assuming a given upper bound on real estate investment and a particular level of standard deviation of the overall portfolio. ${ }^{12}$ By varying these two parameters, Figure 2 is created.

The discrete subprogram corresponds to the choice of which individual properties to include, given this upper bound on real estate investment and $\sigma^{*}$. This subprogram is linked to the nonlinear subprogram, which, given the selection of real estate properties and their corresponding risk-return characteristics, allocates the remaining investment among the three types of financial assets. These subprograms are solved simultaneously using a branch and bound algorithm (see Garfinkel and Nemhauser 1972). Essentially, the branching occurs in the discrete subprogram (selecting the real estate properties) and a nonlinear subprogram (selecting the investment in financial assets) is solved at each node in the tree. The nonlinear subprogram has two constraints; one is the budget constraint, and the other is the constraint on the standard deviation of the overall portfolio. This simple subprogram is solved via the alternating directions method.

\footnotetext{
${ }^{11}$ For tractability and to retain our focus on the role of real estate investment, we restrict our attention to equity and bond indices rather than broader security and bond selection decisions.

${ }^{12}$ A total portfolio investment size of $\$ 250$ million was chosen. This figure was selected based on the relative sizes of the real estate properties in our dataset. Too large a total size would result in almost no variation in the portfolio selection as a* increases (since all the "good" properties have already been selected); too small a size would preclude the larger properties from being selected. From this budget, the amount allocated to real estate is allowed to vary at levels of $3 \%, 6 \%, 9 \%, 12 \%$ and $15 \%$.
} 
The resulting algorithm known as the exact algorithm is implemented in Borland $\mathrm{C}++$ and generates sequences of points on the efficient frontier. ${ }^{13}$ One aspect of the optimization algorithm that significantly reduces the computational burden is the order in which programs are solved. The programs are solved from the least to the most constrained. At each iteration, the previous solution provides upper bounds for any subsequent program. This is similar to the approach developed in Granot, Granot and Kallberg (1979).

More specifically, the program creates an initial upper bound by solving the unconstrained problem. This unconstrained solution provides an upper bound (and an initial infeasible solution) for the solution of any constrained problem. Successive "best" constraints are generated to create new nodes until a feasible solution is reached. At each iteration, this procedure is repeated; the previous, less constrained problem providing simultaneously an upper bound and a starting point for the next program.

Figure 2 - Efficient frontier using mixed zero-one nonlinear program.

A mixed zero-one nonlinear optimization program using a branch and bound algorithm is employed to generate the mixed asset efficient frontier. Each point on the efficient frontier is created assuming a $\$ 250$ million upper bound on real estate investment and a particular level of standard deviation of the overall portfolio. From this $\$ 250$ million budget, the amount allocated to real estate is allowed to vary at levels of $3 \%, 6 \%, 9 \%, 12 \%$ and $15 \%$. Each efficient frontier corresponds therefore with a different level of real estate investment.

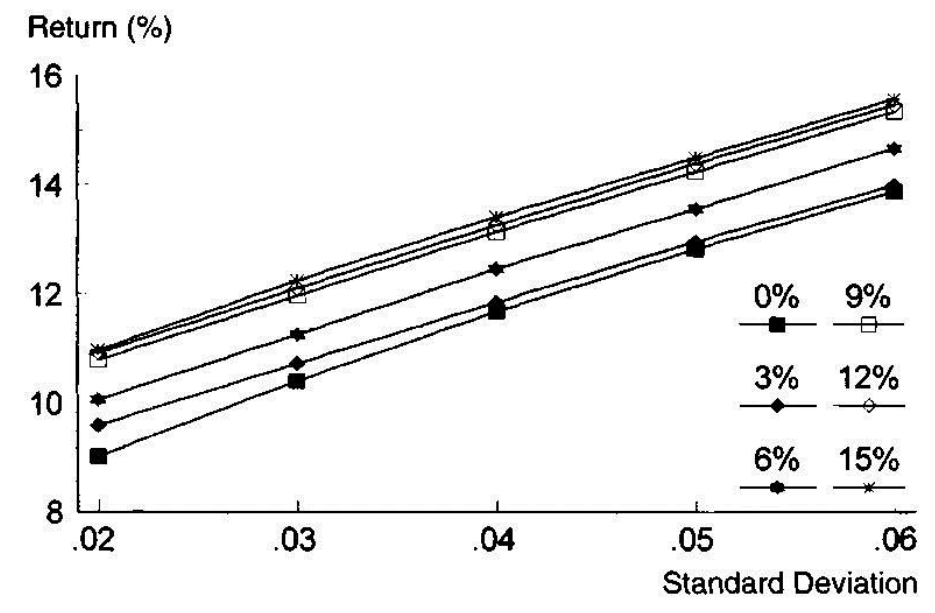

\section{Results}

Table 2 groups the twenty-two properties used in the study into four classes according to initial market value and reports the statistics associated with the modified IRR for each of these classes. Each of the first three classes consists of six properties while there are four properties in the last class. The mean value size in quartile four is at least nine times larger than the other three categories with properties in group four having an average initial appraised value of

\footnotetext{
${ }^{13}$ A point on the efficient frontier is generated in under five seconds using a 486 machine with a math coprocessor.
} 
$\$ 64.16$ million, compared to an average initial value of $\$ 7.14$ million for the next largest size quartile. The most distinguishing result in Table 2 is that the correlation of real estate with Tbills, stocks and bonds is the most negative for smaller-valued properties. As the value of the property increases, there is a tendency for the correlation between real estate and all financial assets to change sign from negative to positive in general as well as to increase in magnitude. This suggests that if the MIRR is the "correct" return measure for constructing portfolios, then smaller properties are most useful for diversifying a portfolio consisting of stocks, bills and bonds. Larger, "trophy properties" are less beneficial as a diversification tool because this type of real estate appears to move in tandem with other financial assets. ${ }^{14}$ These findings, therefore, imply not only that a real estate portfolio should be diversified by value, but also that an investor can either increase or decrease the correlation with real estate by tilting his portfolio toward stocks or bonds depending on the relative proportion of large value versus small value properties in the mixed asset portfolio. A complementary result is that smaller properties give lower correlations with stocks, T-bills and bonds without necessarily sacrificing either returns or risk relative to larger properties. A "size effect" thus exists for real estate. These informal remarks are substantiated in the following optimization section.

Table 2 - Correlation of properties with other assets by property size (value); size (in $\$$ millions).

\begin{tabular}{|c|c|c|c|c|c|}
\hline \multicolumn{6}{|c|}{ Panel A: Modified IRR. } \\
\hline \multicolumn{2}{|c|}{ Avg. Initial Value (\$) } & 2.36 & 3.69 & 7.14 & 64.16 \\
\hline \multicolumn{2}{|c|}{ Number of Observations } & 6 & 6 & 6 & 4 \\
\hline \multicolumn{2}{|c|}{ Range (\$M) } & $<3$ & $3-5$ & $5-10$ & $>10$ \\
\hline \multicolumn{2}{|l|}{ Mean Return } & .14 & .10 & .15 & .11 \\
\hline \multicolumn{2}{|l|}{ Standard Deviation } & .09 & .09 & .13 & .10 \\
\hline \multicolumn{2}{|c|}{ Correlation with T-Bills } & -.68 & .10 & .59 & .38 \\
\hline \multicolumn{2}{|c|}{ Correlation with Stocks } & -.30 & .22 & -.14 & .44 \\
\hline \multicolumn{2}{|c|}{ Correlation with Bonds } & -.05 & -.14 & .09 & .34 \\
\hline \multicolumn{6}{|c|}{$\begin{array}{l}\text { Panel B: Average annual means, standard deviations and correlations for other asset } \\
\text { classes. }\end{array}$} \\
\hline Asset Category & Mean & S.D. & Stocks & Bonds & T-Bill \\
\hline Common Stocks & .19 & .11 & 1.00 & .63 & .06 \\
\hline AAA-Bonds & .13 & .10 & .63 & 1.00 & .19 \\
\hline T-Bills & .08 & .02 & .06 & .19 & 1.00 \\
\hline
\end{tabular}

The results in Table 2 differ from those of Hartzell, Hekman and Miles (1986), who find that the correlation of real estate to stocks and bonds are not only negative across all property sizes but also appear to exhibit no systematic relationship to property size. However, their correlation of real estate to T-bills across property size is consistent with the findings in this study. The difference in results is attributable in part, to the fact that the correlations used in this study annualized data, whereas the study of Hartzell, Hekman and Miles relied on quarterly observations. A problem with using quarterly data is that it suffers from attenuation bias due to the step-like valuation function shown in Figure 1, which dampens the relationship of real

\footnotetext{
${ }^{14}$ One plausible explanation for this is that the tenants of larger "trophy properties" tend to be blue chip corporations whose stocks and bonds are traded on a major exchange and therefore the cash flows of larger properties to some extent tend to move with the cash flows of the corporations occupying the space.
} 
estate to stocks and bonds toward zero. In other words, the use of quarterly data creates more noise, which lessens the statistical significance of the correlations.

A different perspective on the diversification potential of real estate is shown in Table 3. Table 3 shows that there are benefits associated with diversifying within real estate both in terms of property types and also in terms of different economic bases located in different cities in different regions. ${ }^{15}$ This result is consistent with that of previous studies such as Hartzell, Hekman and Miles (1986) and Firstenberg, Ross and Zisler (1988).

Table 3 Intra-real estate correlations using MIRR.

Panel A: Correlation of annual returns on properties by property type.

\begin{tabular}{lccc}
\hline & Industrial & Retail & Office \\
\hline Industrial & 1.00 & & \\
Retail & .21 & 1.00 & \\
Office & .18 & .32 & 1.00 \\
\hline
\end{tabular}

Panel B: Correlation of annual returns on properties by city.

\begin{tabular}{lrrrr}
\hline & East & Midwest & South & West \\
\hline East & 1.00 & & & \\
Midwest & .45 & 1.00 & & \\
South & .73 & -.06 & 1.00 & \\
West & .17 & .39 & -.25 & 1.00 \\
\hline
\end{tabular}

Figure 3 augments Tables 2 and 3, showing the risk and return tradeoff for real estate (classified according to economic region) and financial assets. Even though it is apparent in this figure that the west dominates the east and real estate in the midwest dominates properties located in the South from a return per unit of risk perspective, a real estate portfolio consisting of all four economic regions is advantageous because of the relatively low or negative correlation among returns in the Midwest, South and West, as well as a low correlation between returns in the East and West (see-Table 3). The correlation between real estate returns in the east and midwest is also moderate.

\footnotetext{
${ }^{15}$ The cities are disguised and categorized in terms of region of the country.
} 
Figure 3 - Risk versus returns for different asset classes.

The risk and return tradeoff for real estate is classified according to economic region and property type.

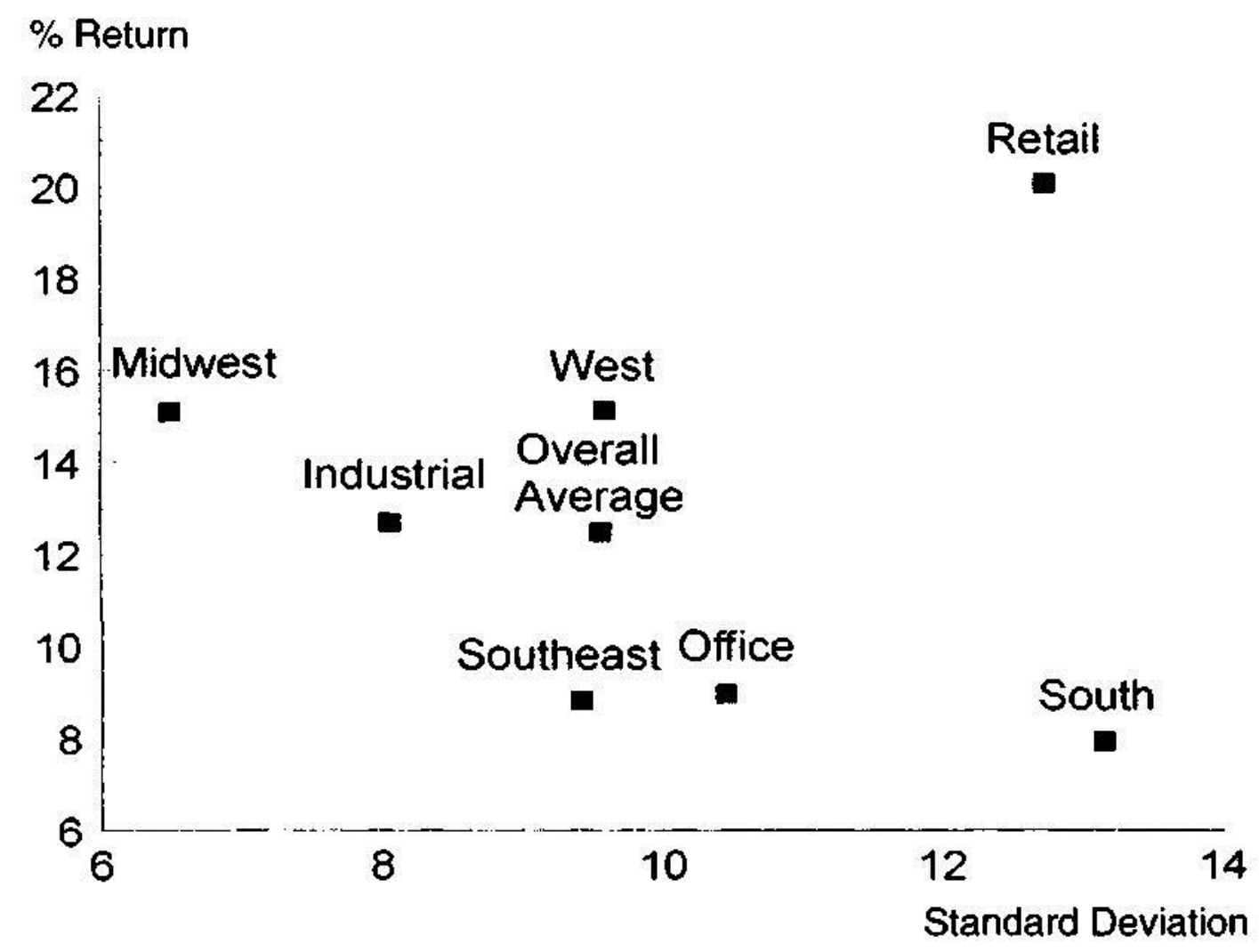

Although a "size effect" is present, Figure 4 reveals that there does not appear to be an analogy to the "small firm effect" in real estate. The small firm effect is evidenced by higher risks and returns associated with smaller firms due in part to a lack of information and a lack of liquidity. With the exception of three outliers on the lower right hand side of the figure, all other observations appear to form no discernible pattern.

Does Size Matter? Is Bigger Necessarily Better?

What are the portfolio implications of this "size effect" for real estate? Smaller properties are chosen over larger properties and when no more attractive, relatively "smaller properties" are available for inclusion in the optimal mixed asset portfolio, the proportion allocated to real estate appears to "stall" at about $9 \%$ as shown in Table 4 and Figure 2 . This is not surprising, recalling from Table 2 that smaller properties not only have lower correlations with stocks and bonds relative to large properties but also have returns and risk similar to larger properties. 
Figure 4 - Non-existence of small firm effect for real estate.

If the small firm effect is present, smaller firms should have higher risks and returns relative to larger firms.

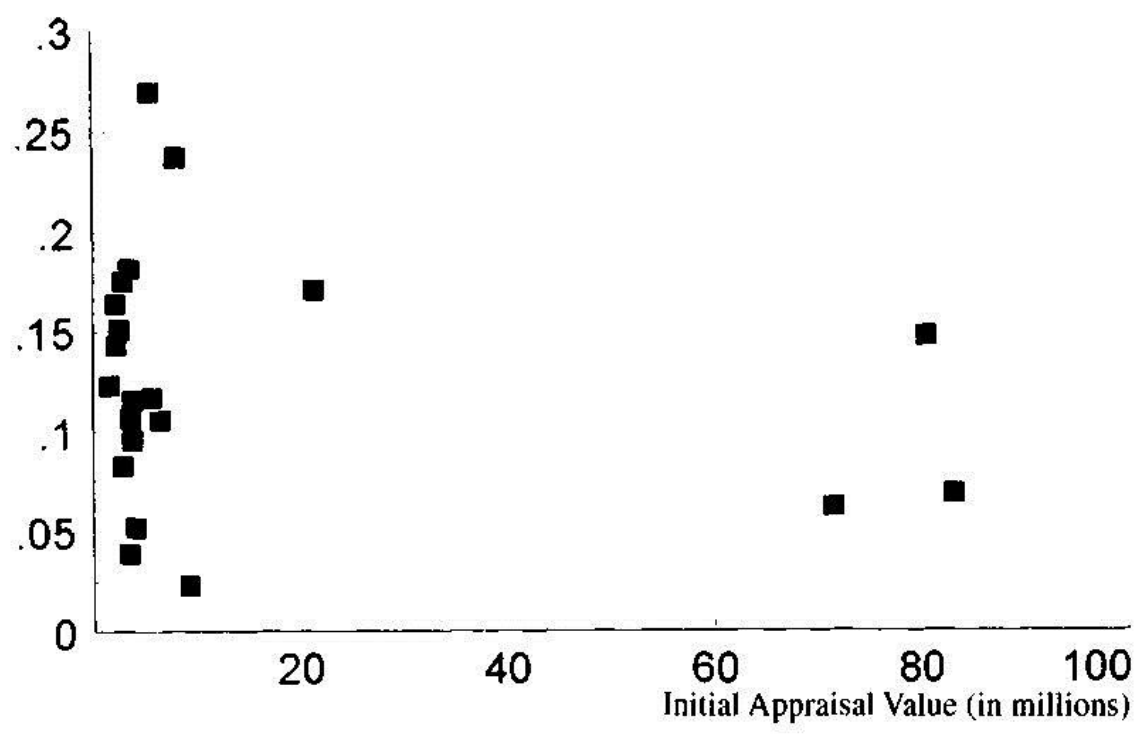

This result is somewhat lower than the previous findings of Fogler (1984); Firstenberg, Ross and Zisler (1988); and Ennis and Burik (1991) that real estate should comprise approximately $20 \%$ of an efficiently diversified portfolio on average given that most institutional portfolios have a target return of around $13 \%-15 \%$. Is $9 \%$, the optimal allocation for real estate? Not necessarily, since the $9 \%$ allocation to real estate could conceivably increase if more small properties with similar mean-covariance characteristics to those in the dataset were available. Thus, the $9 \%$ constraint is not necessarily binding. One important caveat to keep in mind is that the poor performance of the relatively large properties might not be representative of large properties in general.

\section{Heuristics}

As an alternative to the preceding allocation procedure, a heuristic approach is also used to reflect the practice of many firms that do not solve the problem of allocating resources into real and financial assets simultaneously. Firms frequently establish an amount to allocate to real estate and then solve the purely discrete program. The resulting real estate portfolio is then used to allocate the remaining budget into financial assets. This separation is suboptimal, most importantly, because it ignores the fact that different properties exhibit different correlations with financial assets than other properties. Without recognizing these individual characteristics, much of the possible diversification benefit of real estate is lost. To test whether this effect was significant, this heuristic approach, which hereafter is referred to as the separation heuristic, is compared to the previous exact solution. In solving the pure 0 - 1 program, a given budget and an upper bound on the standard deviation are assumed. The resulting portfolio of real estate is then used to optimize over the remaining budget allocated to financial assets. 
Table 4 a comparison of algorithms for selecting real estate (returns on mixedasset portfolio).

\begin{tabular}{|c|c|c|c|c|c|c|}
\hline \multirow[b]{2}{*}{$\%$ R.E. } & \multicolumn{2}{|c|}{ Portfolio Return } & \multirow[b]{2}{*}{$\begin{array}{l}\text { Separation } \\
\text { Heuristic }\end{array}$} & \multicolumn{2}{|c|}{$\begin{array}{l}\text { \% Error in Certainty } \\
\text { Equivalents }\end{array}$} & \multirow[b]{2}{*}{$\gamma=.1$} \\
\hline & St. Dev. & Exact & & $\begin{array}{l}\text { E-S Spread } \\
\text { (Basis Pts) }\end{array}$ & $\gamma=1$ & \\
\hline $3 \%$ & $\begin{array}{l}.03 \\
.04 \\
.05 \\
.06\end{array}$ & $\begin{array}{l}.11 \\
.12 \\
.13 \\
.14\end{array}$ & $\begin{array}{l}.11 \\
.12 \\
.13 \\
.14\end{array}$ & $\begin{array}{l}7.24 \\
8.45 \\
6.48 \\
3.07\end{array}$ & $\begin{array}{l}.67 \\
.71 \\
.50 \\
.22\end{array}$ & $\begin{array}{l}.68 \\
.71 \\
.50 \\
.22\end{array}$ \\
\hline Average & & & & 6.31 & .52 & .53 \\
\hline $6 \%$ & $\begin{array}{l}.03 \\
.04 \\
.05 \\
.06\end{array}$ & $\begin{array}{l}.11 \\
.12 \\
.14 \\
.15\end{array}$ & $\begin{array}{l}.11 \\
.12 \\
.13 \\
.14\end{array}$ & $\begin{array}{r}8.45 \\
16.84 \\
19.04 \\
23.93\end{array}$ & $\begin{array}{r}.75 \\
1.34 \\
1.39 \\
1.61\end{array}$ & $\begin{array}{r}.75 \\
1.35 \\
1.40 \\
1.63\end{array}$ \\
\hline Average & & & & 17.07 & 1.27 & 1.28 \\
\hline $9 \%$ & $\begin{array}{l}.03 \\
.04 \\
.05 \\
.06\end{array}$ & $\begin{array}{l}.12 \\
.13 \\
.14 \\
.15\end{array}$ & $\begin{array}{l}.11 \\
.13 \\
.14 \\
.15\end{array}$ & $\begin{array}{l}62.01 \\
30.27 \\
12.57 \\
26.86\end{array}$ & $\begin{array}{r}5.17 \\
2.30 \\
.88 \\
1.73\end{array}$ & $\begin{array}{r}5.18 \\
2.30 \\
.88 \\
1.75\end{array}$ \\
\hline Average & & & & 32.93 & 2.52 & 2.53 \\
\hline $12 \%$ & $\begin{array}{l}.03 \\
.04 \\
.05 \\
.06\end{array}$ & $\begin{array}{l}.12 \\
.13 \\
.14 \\
.16\end{array}$ & $\begin{array}{l}.12 \\
.13 \\
.14 \\
.15\end{array}$ & $\begin{array}{l}42.89 \\
40.69 \\
40.69 \\
27.61\end{array}$ & $\begin{array}{l}3.53 \\
3.05 \\
2.80 \\
1.76\end{array}$ & $\begin{array}{l}3.54 \\
3.07 \\
2.83 \\
1.78\end{array}$ \\
\hline Average & & & & 37.97 & 2.79 & 2.81 \\
\hline $15 \%$ & $\begin{array}{l}.03 \\
.04 \\
.05 \\
.06\end{array}$ & $\begin{array}{l}.12 \\
.13 \\
.15 \\
.16\end{array}$ & $\begin{array}{l}.12 \\
.13 \\
.14 \\
.15\end{array}$ & $\begin{array}{l}16.59 \\
16.59 \\
14.79 \\
10.98\end{array}$ & $\begin{array}{r}1.35 \\
1.23 \\
1.01 \\
.70\end{array}$ & $\begin{array}{r}1.35 \\
1.24 \\
1.02 \\
.70\end{array}$ \\
\hline $\begin{array}{l}\text { Average } \\
\text { Overall }\end{array}$ & & & & $\begin{array}{l}14.74 \\
21.80\end{array}$ & $\begin{array}{l}1.07 \\
1.63\end{array}$ & $\begin{array}{l}1.08 \\
1.64\end{array}$ \\
\hline
\end{tabular}

E-S Spread is the spread in the mixed asset portfolio return using the exact algorithm versus using the separation heuristic (heuristic 1) for choosing properties for a given level of risk. The \% error in certainty equivalents is equal to the certainty equivalent (C.E.) of the exact solution minus the C.E. of the approximate solution and this difference is divided by the C.E. of the exact solution. \% R.E. is the percentage of real estate in the mixed asset portfolio consisting of Treasury bills, stocks and bonds.

To compare the accuracy of the exact versus the approximate solutions given in Table 4, not only were the spread in returns between the exact solution relative to the heuristic solution for a given level of risk examined, but a utility based approach was used. In this analysis, the investor is assumed to have a constant relative risk aversion utility function ${ }^{16}$ of the form

$$
\max _{d}=(S, B, \bar{x}) \mu(\omega)=\omega^{\beta}
$$

which means that the relative risk aversion is $(1-y)$. Now, assuming an initial wealth of 1 and that $\log (W)$ is normally distributed with mean is $\mu$ and variance $\sigma^{2}$, it can be shown (see Ingersoll 1987) that the expected utility is

\footnotetext{
${ }^{16}$ Constant relative risk aversion means that the proportion of wealth invested in the risky asset is invariant with respect to changes in the investor's initial level of wealth. The power function used also has the property of decreasing absolute risk aversion which means that an investor will invest more money (in absolute dollars) in risky assets as wealth increases.
} 


$$
E U=\exp \left[\gamma \mu+\gamma^{2} s^{2} / 2\right] / \gamma
$$

This expression is used to compute the certainty equivalent at levels of relative risk aversion, ranging from 0 to .9 , to determine the percentage difference between the exact and the approximate solution.

How does using the separation heuristic perform from a risk-return perspective relative to the exact mixed integer nonlinear algorithm which simultaneously optimizes stocks, bonds and real estate? The separation heuristic performs surprisingly well compared to the exact solution. At a $3 \%$ allocation to real estate, Table 4 shows that only six basis points separate the returns on a mixed asset portfolio using the exact solution relative to the heuristic solution for a given level of risk. From a certainty equivalent perspective, this translates to only .5\% error discrepancy on average. This certainty equivalent error is relatively constant regardless of the level of relative risk aversion chosen. ${ }^{17}$ The difference in the spread rises as the percentage in real estate increases with the average spread going from seventeen basis points for a $6 \%$ property allocation to thirty-eight basis points for a $12 \%$ allocation in real estate. However, this spread declines to about fifteen basis points on average when real estate comprises $15 \%$ of the mixed asset portfolio. In terms of the percentage error in certainty equivalents, the exact solution differs from the approximate solution by about $1.3 \%$ at the $6 \%$ level increasing to $2.5 \%(2.7 \%)$ at the $9 \%(12 \%)$ level and then decreasing to approximately $1 \%$ at the $15 \%$ level on average. Although there is a wider variability when the certainty equivalent error is examined for individual standard deviations, the highest percentage error is at $5 \%$ for a $9 \%$ investment in real estate at a 3\% standard deviation, and this occurs only once. The next highest percentage error in certainty equivalents is at 3.5\% (12\% real estate at $3 \%$ standard deviation).

Thus, the difference in returns on a mixed asset portfolio using this heuristic is small relative to the estimation error that exists in real estate returns whether one measures the difference between the exact versus the approximate solution either in terms of the spread or alternatively, in terms of the percentage error in certainty equivalents. This is especially true for real estate allocations of $3 \%, 6 \%$ and $15 \%$. This result is intuitively reasonable. The differences in the return on the mixed asset portfolio using a 3\%-6\% allocation to real estate are due not only to the fact that a small portion of the portfolio is devoted to real estate but also because both algorithms choose small properties which are "good" from a mean-variance perspective. At a $15 \%$ allocation to real estate, essentially all the "good" properties are selected and therefore the spread between using the exact technique versus the separation heuristic to selecting real estate is relatively narrow. In the $9 \%-12 \%$ real estate range, the spread in basis points (percentage error in certainty equivalents) increases as the result of effectively using information about the intercorrelations between the return on each property relative to the returns on stocks and bonds. ${ }^{18}$ The incremental diversification advantage of small properties is

\footnotetext{
${ }^{17}$ To simplify the analysis, only the two polar cases of relative risk aversion are considered.

${ }^{18}$ In other words, at higher allocations to real estate, more "mediocre" properties are left and therefore the two algorithms tend to diverge since the exact method uses information about intra-real estate correlations as well as inter-asset correlations, while the separation heuristic uses only information on intra-property correlations. The
} 
evident in Table 4. For any given allocation to real estate, especially in the $9 \%-15 \%$ range, the lower the level of portfolio risk, the more smaller properties are allowed to come into the mixed asset portfolio. In summary, small properties have lower correlations with financial assets and this is captured in the exact solution but not necessarily in the separation heuristic to selecting "optimal" properties.

\begin{tabular}{|c|c|c|c|c|}
\hline$\%$ in Real Estate & St. Dev. & T-Bills & Stocks & Bonds \\
\hline $3 \%$ & $\begin{array}{l}.03 \\
.04 \\
.05 \\
.06\end{array}$ & $\begin{array}{l}.65 \\
.53 \\
.39 \\
.28\end{array}$ & $\begin{array}{l}.35 \\
.47 \\
.60 \\
.71\end{array}$ & $\begin{array}{l}.00 \\
.00 \\
.01 \\
.01\end{array}$ \\
\hline $6 \%$ & $\begin{array}{l}.03 \\
.04 \\
.05 \\
.06\end{array}$ & $\begin{array}{l}.65 \\
.51 \\
.37 \\
.24\end{array}$ & $\begin{array}{l}.35 \\
.48 \\
.63 \\
.76\end{array}$ & $\begin{array}{l}.00 \\
.02 \\
.00 \\
.00\end{array}$ \\
\hline $9 \%$ & $\begin{array}{l}.03 \\
.04 \\
.05 \\
.06\end{array}$ & $\begin{array}{l}.59 \\
.47 \\
.33 \\
.20\end{array}$ & $\begin{array}{l}.38 \\
.53 \\
.65 \\
.79\end{array}$ & $\begin{array}{l}.02 \\
.00 \\
.02 \\
.01\end{array}$ \\
\hline $12 \%$ & $\begin{array}{l}.03 \\
.04 \\
.05 \\
.06\end{array}$ & $\begin{array}{l}.59 \\
.46 \\
.31 \\
.18\end{array}$ & $\begin{array}{l}.38 \\
.54 \\
.68 \\
.81\end{array}$ & $\begin{array}{l}.02 \\
.00 \\
.01 \\
.01\end{array}$ \\
\hline $15 \%$ & $\begin{array}{l}.03 \\
.04 \\
.05 \\
.06\end{array}$ & $\begin{array}{l}.62 \\
.43 \\
.33 \\
.19\end{array}$ & $\begin{array}{l}.38 \\
.55 \\
.67 \\
.81\end{array}$ & $\begin{array}{l}.00 \\
.02 \\
.00 \\
.00\end{array}$ \\
\hline
\end{tabular}

When the optimal proportion of T-bills, stocks and bonds was examined at a given allocation to real estate, a very small percentage was found to be allocated to bonds. For any given allocation to real estate, Table 5 shows that T-bills dominate low risk portfolios while funds are shifted into stocks at higher risk levels due to higher returns for stock coupled with smaller inter-asset correlations for stocks compared to bonds as reported in Table 2.

\section{Caveats About Study Findings}

The results of this analysis are conditioned on the mean-variance characteristics of properties in the dataset. As such, our conclusions are sensitive to the real estate assets selected. This is especially true of the finding that smaller properties do not appear to have higher risks and offer better diversification advantages relative to larger properties. Almost all of the larger properties did not perform well in a mean-variance context. Further validation of the findings is therefore required.

\section{Conclusion}

separation algorithm has an average reduction in mean returns of 15-38 basis points relative to the exact solution. Stated differently, the exact solution will reduce the error rate by approximately $2.5 \%$ on average $(5 \%$ in the one extreme case) relative to the approximate solution. 
The present study explores the role of real estate investment in a mixed asset portfolio problem using two alternative approaches. These algorithms recognize the indivisible or lumpy asset nature of directly investing in real estate and no short sales. This study concentrated on a cash flow approach to the mixed asset portfolio problem using the modified IRR and a longer term holding period (one year). This analysis led to several new insights regarding optimal real estate portfolios. One distinctive finding is that a "size effect" is present. The incremental diversification benefits that real estate brings to a mixed asset portfolio diminishes the larger the value of the real properties used for diversification purposes. Smaller properties not only have lower correlations with other financial assets on average but also have similar risks and returns relative to larger properties. The optimal allocation of real estate is $9 \%$ for the sample although this allocation could possibly increase if more small properties with similar meancovariance attributes to those in the dataset are available. When the real estate portfolio is optimized separately and then used to subsequently optimize over all other financial assets, portfolio returns are twenty-two basis points lower on average for a given level of risk, compared to simultaneously optimizing over all assets. This suggests that the separation heuristic to selecting real estate represents a good approximation given that estimation error exists in real estate returns. However, both algorithms result in reasonably similar returns on a mixed asset portfolio for a given level of risk if only $3 \%-6 \%$ is allocated to real estate. A noticeable divergence in returns occurs at higher allocations to real estate due to differences among the algorithms in using information about intra- and inter-asset correlations of returns. However, this return differential translates to an error rate in certainty equivalent terms of only 2.5\%-2.7\% on average. A final contribution of this study is the finding that high investments in bonds may not be optimal when mixed asset portfolios contain real estate. The results suggest that the optimal portfolio including real estate tends to contain a high level in T-bills at low levels of risk and a high proportion in equities at higher risk levels.

This paper was written to rejuvenate as well as perpetuate the ideas of the late James $A$. Graaskamp of the University of Wisconsin. We wish to thank Kerry Vandell and James Shilling for providing financial assistance for this research project.

\section{References}

Bajtelsmit, V.L. and E.M. Worzala. 1995. Portfolio Decision-Making by Pension Fund Managers: A Survey of Corporate, Public, and Union Plans. Colorado State University Working Paper: Fort Collins, CO.

Ennis, R.M. and P. Burik. 1991. Pension Fund Real Estate Investment Under a Simple Equilibrium Pricing Model. Financial Analysts Journal May-June: 20-30.

Findlay, III, M. Chapman, C.W. Hamilton, S. Messner and J.S. Yormark. 1979. Optimal Real Estate Portfolios. Journal of the American Real Estate and Urban Economics Association 7(3): 298-317. 
Fogler, H.R. 1984. 20\% in Real Estate: Can Theory Justify It? Journal of Portfolio Management Winter: 6-13.

Friedman, H.C. 1971. Real Estate Investment and Portfolio Theory. Journal of Financial and Quantitative Analysis 6(2): 861-874.

Firstenberg, P., S. Ross and R. Zisler. 1988. Real Estate: The Whole Story. Journal of Portfolio Management 14(3): 22-34.

Garfinkel, R.S. and G.L. Nemhauser. 1972. Integer Programming. John Wiley and Sons: New York, NY.

-------. 1979. The Evolution of Income Property Yield Analysis. Crocker H. Liu and Karl Hilgendorf (eds.). The Gospel of Real Estate Equity Investment According to King James.

Daniel G., F. Granot and J. Kallberg. 1979. Covering Relaxation for Zero-One Polynomial Problems. Management Science 25(3): 710-723.

Hartzell, D.J., J. Hekman and M. Miles. 1986. Diversification Categories in Investment Real Estate. Journal of the American Real Estate and Urban Economics Association 14(2): 230-254.

Hoag, J. 1980. Towards Indices of Real Estate Value and Return. Journal of Finance 35(2): 569580.

Ibbotson Associates. 1991. SBBI 1991 Yearbook. Ibbotson Associates: Chicago, IL.

Ingersoll, J. 1987. Theory of Financial Decision Making. Rowan and Littlefield: Totowa, NJ.

Ross, S. and R. Zisler. 1991. Risk and Return in Real Estate. Journal of Real Estate Finance and Economics 4(2): 175-190. 